\title{
Interpreting traumatic narratives of unaccompanied child migrants in the United States: Effects, challenges and strategies
}

\author{
Indira Sultanić \\ Virginia Commonwealth University \\ isultanic@vcu.edu \\ https://orcid.org/0000-0001-9158-0802
}

\begin{abstract}
This research examines the challenges of interpreting for unaccompanied child migrants in the United States and the effect of exposure to the traumatic narratives told by these children, as experienced by the interpreters involved. When a traumatic narrative is introduced, over time it has an effect on the emotional and psychological well-being of an interpreter. This study therefore focuses on the coping mechanisms interpreters employ to minimize the effects of long-term exposure to the traumatic content when they work in settings involving migrant children. During the past few decades, a number of studies have been conducted on the emotional and psychological effects of traumatic content on interpreters who work in various contexts, but very few have focused on interactions involving this vulnerable group of migrants. This study uses a qualitative approach in which data were collected through semi-structured interviews with both trained and ad hoc interpreters who work or have worked with unaccompanied children seeking asylum in the United States since the summer of 2014. The study contributes to the growing body of literature on public service interpreting. It does so by offering the interpreter's perspective on the specific challenges and difficulties of interpreting for unaccompanied child migrants in that country who face near-insurmountable systemic barriers and challenges. It sheds light on the delicate nature of interpreting for vulnerable groups, especially children, who are seeking asylum there. Furthermore, it brings into focus the applicable strategies that help interpreters prepare for interpreting traumatic experiences, and also for coping both during the act of interpreting and afterwards.
\end{abstract}

Keywords: interpreting in asylum, trauma-informed settings, refugee children, interpreting for unaccompanied minors, interpreting and emotional labor, interpreting for vulnerable populations 
Sultanić, I. (2021). Interpreting traumatic narratives of unaccompanied child migrants in the United States: Effects, challenges and strategies. Linguistica Antverpiensia, New Series: Themes in Translation Studies, 20, 227-247.

\section{Introduction}

According to UNICEF (2018, August), between 2013 and 2014, a total of 68,400 unaccompanied migrant children crossed the border between Mexico and the United States. The total number of unaccompanied migrant children apprehended at the Southwest Border in Fiscal Year (FY) 2020, according to the US Customs and Border Protection data (CBP, n.d.), was 30,557, with the majority of the children originating from Mexico, Honduras, El Salvador and Guatemala. In March 2020, owing to the potential health risks associated with COVID-19, the CBP began, under Title 8 Enforcement Actions and Title 42 Expulsions, "prohibiting the entry of certain persons who potentially pose a health risk" and expelling them "to their country of last transit" or to the "person's country of origin". Although COVID-19 has caused a significant decrease in the total number of asylum seekers, the migration wave that began in 2013 has led to a growing demand for pro bono legal representation at all stages of the asylum process, and also for professional and ad hoc interpreters.

The asylum process in the United States is quite complicated and presents a challenge to any person with limited English proficiency (LEP). There are two ways to obtain asylum: the first is through the "affirmative process", which is "processed with US Citizenship and Immigration Services (USCIS)", in which case "a decision is made by an asylum officer"; the second is through a "defensive process", where the asylum case is "processed with the Executive Office for Immigration Review (EOIR)" (see Killman, 2020, p. 78, for more). Both processes, as Killman (2020) points out, require legal representation and interpreting services (p. 78). Regardless of whether one is seeking asylum through the affirmative or the defensive process, the story-gathering, which also becomes the client's testimony, is the most important component in an asylum case (Killman, 2020).

This process of story-gathering is extremely important for building an asylum seeker's case. As Pöllabauer (2004) has argued regarding asylum hearings in Austria, "it is vital to present their claims in a plausible, coherent and non-contradictory way" (p. 146). Furthermore, without interpreters, miscommunication is more likely to occur, can result in repatriation and can be "tantamount to a death sentence" for an asylum seeker (pp. 143-144).

According to the American Immigration Council (2020), the client's testimony is usually founded on the "credible fear" or the "reasonable fear" interview or a fear of persecution in the country of origin (pp. 3-4). When the asylum-seeking individual is a minor, often with a limited lexicon, who has witnessed and experienced unimaginable tragedy and violence in their home country and on their journey to safety, it can be difficult to gather their story, even when an interpreter is present. Their trauma alone can make it difficult to recount the events of what happened to them in detail; but when that is combined with their age, communication skills, general stress and the anxiety of being questioned by immigration officers, usually in the company of other unfamiliar individuals such as the interpreter present in the room, the situation is exacerbated (see Powell et al., 2017, for more).

Therefore, interpreting in these settings presents many challenges. In some cases, the children may be in their early stages of native language acquisition but also have a limited conceptualization of the world and are therefore unable to answer questions posed and 
Sultanić, I. (2021). Interpreting traumatic narratives of unaccompanied child migrants in the United States: Effects, challenges and strategies. Linguistica Antverpiensia, New Series: Themes in Translation Studies, 20, 227-247.

provide clarifications using language that is not adjusted for them. In some cases, the child is a speaker of an indigenous language with limited or no knowledge of Spanish, yet interpreting is provided only in Spanish. In addition, although children can adapt, according to Nilsen (2015), a "child's participation is dependent primarily on his or her understanding and acceptance of the system of turn-taking that is fundamental to consecutive interpretation" (p. 125).

Furthermore, their participation in interpreter-mediated interviews may also depend on whether the interviewer, or the interpreter, finds their asylum claim credible, as has been documented in studies conducted in Sweden (Keselman et al., 2008, 2010a, 2010b).

In addition to the challenges of story-gathering arising from the asylum seekers' status as children (see Nilsen, 2015, p. 125, for more), in these settings it can also be further complicated by the interpreter's status and their background, history of trauma, training and the professional standards and ethics to which they adhere. In the United States, most professional interpreters who work with asylum seekers will be familiar either with a code of ethics and standards of practice for healthcare interpreters (such as the National Council on Interpreting in Health Care (or $\mathrm{NCIHC}$ ), the California Healthcare Interpreting Association (or CHIA) and the International Medical Interpreters Association (or IMIA) or with the code of ethics for court interpreters set down by the National Association of Judiciary Interpreters and Translators (or NAJIT). The context in which one interprets, and the interpreter's educational background, dictates the code or standard of practice one adheres to. To my knowledge, there are currently no best practices, standards, codes of ethics or training programs in the United States specifically designed for interpreting work with unaccompanied refugee children.

Aside from the challenge of interpreting these children's utterances and inferring meaning from these narratives to "forge understanding" (Pöllabauer, 2015, p. 208), interpreters are also the first to hear stories and narratives with traumatic content, which can have both immediate and long-term adverse effects. Many interpreters may have a history of their own trauma or a lived experience, and the use of the first person while interpreting traumatic content can lead to distress or re-traumatization (Crezee et al., 2011). Some interpreters may have coping strategies they employ during or following a difficult interpreted event, as documented by Lai and Costello (2020, p. 77), whereas others may not.

These coping strategies are operationally defined as any self-identified or self-taught technique that helps an interpreter maintain their composure and neutrality while accurately retelling an asylee's story in the first person during an interpreted event. They could also include any technique that an interpreter uses to reduce the duration of the traumatic effect that the retelling may have on them beyond the interpreted event. Some of these strategies for trained professional interpreters may be informed by their understanding of their role as a communication go-between and their understanding of the boundaries of their role as an interpreter, as per their professional standard of practice or code of ethics. For ad hoc or nonprofessional interpreters or language assistants these strategies may be informed by their experience in adjacent service professions (social work, advocate, case worker, etc.). They may already have self-care techniques which they may or may not identify as specific coping 
Sultanić, I. (2021). Interpreting traumatic narratives of unaccompanied child migrants in the United States: Effects, challenges and strategies. Linguistica Antverpiensia, New Series: Themes in Translation Studies, 20, 227-247.

strategies. Some contexts may also have support structures for interpreters, whereas others may not.

To that end, this study aims to answer the following questions: (1) What are the interpreterperceived effects of exposure to the harrowing narratives of migrant children on the interpreter's well-being?; (2) What challenges and difficulties do interpreters face when interpreting for children at any stage of the asylum process?; and (3) What coping strategies and mechanisms do interpreters employ to maintain their composure and remain within the parameters of their professional role in these contexts?

\section{Literature review}

Studies have been conducted on interpreter-mediated interviews with children (Nilsen, 2013, 2015), asylum-seeking minors in Sweden (Keselman et al., 2008, 2010a, 2010b), interpretermediated investigative interviews with minors in England (Böser \& LaRooy, 2018) and on the profile, role and expectations of interpreters working with children involved in criminal investigations in Italy (Amato \& Mack, 2017). In addition, a number of studies have been conducted over the past few decades on

- $\quad$ the emotional and psychological effects of traumatic content on healthcare interpreters (Bontempo \& Malcolm, 2012; Loutan et al., 1999);

- $\quad$ public service interpreters (Valero Garcés, 2015);

- $\quad$ the role of the interpreter in asylum hearings (Pöllabauer, 2004);

- $\quad$ interpreters working with refugees (Miller, 2005);

- $\quad$ interpreters and professionals working with refugees in New Zealand and Australia (Crezee et al., 2011);

- $\quad$ ethics and interpreting for refugee children and families (Björn, 2005);

- $\quad$ mental health interpreters (Knodel, 2018; Musacchio, 2013);

- $\quad$ conference and media interpreters (Kurz, 1997, 2002);

- criminal courtroom interpreters (Ndongo-Keller, 2015); and

- $\quad$ interpreter-mediated child sexual abuse interviews (Powell et al., 2017).

In addition, there is an entire volume of studies on interpreting for minors that were conducted in various European contexts (see Balogh \& Salaets, 2015, for more). And yet, few such studies exist which explore the interpreting interactions involving this vulnerable group in the American context.

Trauma, post-traumatic stress disorder (PTSD), compassion fatigue, burnout, vicarious trauma and their effects have been studied at length since the 1980s. However, as observed by many interpreting scholars, most recently by Ndongo-Keller (2015), the effects of exposure to trauma and stress have not been studied widely with respect to interpreters in the United States. This represents a knowledge gap about these topics, one which deserve closer attention from interpreting researchers, trainers and educators.

Research on the topic of vicarious trauma or traumatization (VT) (see Palm et al., 2004, for more) - also known as secondary traumatization (see Birck, 2001; Sexton, 1999, for more), 
Sultanić, I. (2021). Interpreting traumatic narratives of unaccompanied child migrants in the United States: Effects, challenges and strategies. Linguistica Antverpiensia, New Series: Themes in Translation Studies, 20, 227-247.

which is defined as "[negative] transformation in the therapist's (or other trauma worker's) inner experience resulting from empathic engagement with clients' trauma material" (Pearlman \& Saakvitne, 1995, p. 151) - has been increasing in recent years, because more scholars of spoken and signed language interpreting are exploring this topic. Knodel (2018) conducted a study of American Sign Language (ASL) interpreters in mental health settings, focusing on their experience with VT and their coping mechanisms. Most recently, Barreto Abrams (2020) conducted a dissertation study of 201 signed language interpreters working with trauma survivors to measure the effect of VT. What he found was that "sign language interpreters experience psychological needs and cognitive disruption; therefore, contributing to vicarious trauma" (Barreto Abrams, 2020, p. 91). In addition, interpreters who "scored higher than their counterparts" were those who were not certified, had a history of trauma or of "mental health conditions" and those who "work with trauma survivors" (Barreto Abrams, 2020, p. 91).

VT among interpreters working in public service settings has also been studied and explored by several scholars in Australia. Lai et al. (2015) surveyed 271 public service interpreters on the interpreters' perceived effect of exposure to traumatic content. Their participants reported varying degrees of "distress", depending on the number of hours spent per week and the type of traumatic material with which they engaged (pp. 9-10). Their study also examined whether interpreters sought support and, if so, the different types of support they sought to mitigate and to cope with the "impact of traumatizing material" (p. 7). The participants reported seeking a range of support: from family and friends to other interpreters, counselors, and therapists (p. 14). In a study conducted by Crezee et al. (2011) on the issues experienced by interpreters working in refugee settings in New Zealand and Australia, "approximately two-thirds" of the 90 respondents stated having "experienced areas of difficulty when interpreting for individual refugees or groups" (p. 261).

Lor (2012) also conducted an exploratory study on the effects of VT on interpreters working in mental health settings. Although many of the studies mentioned here focus on VT, Lor's study uses the emotional labor framework. More specifically, it is based on the dimensions of emotional labor established by Guy et al. (2008). According to Guy et al. (2008), emotional labor is "a component of the dynamic relationship between two people: worker and citizen or worker and worker" (p. 5). "Emotion work is as individual as cognitive work. It is a skill and is subject to individual differences" (p. 6). They differentiate between cognitive work skills and emotion work skills in that cognitive skill "includes application of factual knowledge to the intellectual analysis of problems and rational decision making" whereas emotional work skill is "decision making in terms of the expression of emotion", which can mean either the "expression" or the "suppression" of emotion in a communicative event (p. 7). Interpreters are required to perform both the cognitive gymnastics and the emotional labor.

Based on the existing literature, it can be argued that interpreter training and educational programs focus more on skill-building and the cognitive load of interpreting than on the emotional aspects of interpreter-mediated encounters. These emotional aspects of interpreting can lead to compassion fatigue, which Boyle (2015) defines as "the cost of caring for others in emotional pain" (p. 49), or to Secondary Traumatic Stress (STS) disorder, which 
Sultanić, I. (2021). Interpreting traumatic narratives of unaccompanied child migrants in the United States: Effects, challenges and strategies. Linguistica Antverpiensia, New Series: Themes in Translation Studies, 20, 227-247.

has been likened to PTSD but results from secondary exposure to traumatic content (Figley, 1995).

This study, like the studies described above, explores the challenges interpreters face when working with refugees, the perceived effects of exposure to traumatic content and their coping mechanisms. While parallels can be drawn between the findings from this study and other similar studies (Crezee et al., 2011; Knodel, 2018; Lai \& Costello, 2020), this study uses the dimensions of emotional labor identified by Guy et al. (2008, pp. 5-6) to help name and classify the different responses of exposure to traumatic content as experienced by the participants. Not all of the dimensions identified by Guy et al. (2008, pp. 5-6) are discussed in detail in this article; however, the following examples are used again in Section 5:

- Caritas: captures the caring function in human services.

- Compassion fatigue: used in social work to describe the burnout resulting from too much caritas.

- Professional face: used to describe the status shield that workers don to distance themselves emotionally from an interaction; it is a role-playing function.

- $\quad$ Show time: similar to game face.

- Rapport: the ability to establish a deep understanding and communication with the other.

- $\quad$ Stage left: refers to playacting in expressing an emotion, as if on stage.

- Emotional suppression: that which is required to disregard one's own feelings.

- Emotional engagement: the ability to connect with the other and empathize.

- Emotional mask: that which results when workers convincingly suppress their own emotions in order to act as if they feel a contradictory emotion, or no emotion.

These dimensions, by definition, apply to a relationship between two people, whereas interpreters typically work in a triad. Interpreters are, however, the first to receive oral or written input in either language, in this way becoming the object of initial exposure. Furthermore, as previously stated, some of these dimensions are already extant in the codes of ethics for healthcare and legal interpreters. Some interpreters may have acquired these as part of their education and training, but the dimensions may also have developed spontaneously as a form of self-preservation, an issue which is discussed in section 5 .

\section{Method}

The data in this study were collected through semi-structured interviews with interpreters who work or have worked with unaccompanied minors in the United States. The interview guide consisted of questions pertaining to the participants' background, exposure, effects and coping strategies, and the type of training and education they had received. The background questions (type of interpreter training completed, if any, years of (non-)professional interpreting experience and years of experience working in settings involving unaccompanied migrant children in the United States) in part served as a screening tool to ensure that those participants who expressed an interest in taking part met the study criteria (see section 3.1). Once participation eligibility was established, the participants were asked questions specific 
Sultanić, I. (2021). Interpreting traumatic narratives of unaccompanied child migrants in the United States: Effects, challenges and strategies. Linguistica Antverpiensia, New Series: Themes in Translation Studies, 20, 227-247.

to the aspects they found the most challenging, the ways in which exposure to the traumatic narratives of migrant children had affected them, the specific strategies they employed to cope with exposure to this content and which of these they felt worked best, and why. Questions regarding training and education on how to work with vulnerable groups were also posed, but they are the focus of a different project and are not discussed in this article.

\subsection{Participants}

This study was approved by the Virginia Commonwealth University Institutional Review Board (IRB). A call for participants was sent via email and shared with translation and interpreting groups on social media. A total of 22 interpreters responded to the call. In order to meet the study criteria, the participants had to be Spanish-English interpreters, at least 18 years old at the time of the interview and have had experience in interpreting for unaccompanied child migrants in the United States since the summer of 2014. Participation in the study was voluntary and the participants were compensated for their time with a payment of $\$ 20.00$. A total of 21 interpreters met the study criteria and were interviewed, one being disqualified because they worked only with adults in asylum settings.

Of those 21 interpreters, 15 reported having received some form of formal interpreter training, while six reported not having been formally trained. The participants provided interpreting services to unaccompanied child migrants in one or more of the following contexts:

- asylum interviews (over-the-phone interpreting (OPI) for Immigration Officers and Child Refugees)

- asylum offices

- immigration attorney-and-client meetings (asylum applications, declarations, storygathering, etc.)

- detention centers (OPI for Immigration Officers and Child Refugees)

- immigration court

- $\quad$ state court

- $\quad$ Special Immigration Juvenile Status (SIJ) hearings

- $\quad$ social services

- shelters

- US-Mexico Border Authorities Offices (OPI)

- inpatient mental health settings

\subsection{Data analysis}

Once the interviews were concluded, they were manually transcribed and anonymized. Main themes began to emerge during the interview process and during the initial data analysis, which was performed using the NVivo software. Because of the richness of the data and the nature of the available NVivo platform, which had limited functionality, additional analysis was also performed manually. This second pass through the data helped to identify additional themes and also helped with selecting examples from the participants for each of the themes. The examples were selected based on the depth of the information provided, but also since 
Sultanić, I. (2021). Interpreting traumatic narratives of unaccompanied child migrants in the United States: Effects, challenges and strategies. Linguistica Antverpiensia, New Series: Themes in Translation Studies, 20, 227-247.

the study is based on interpreters' perceived effects of exposure to difficult content. Some examples were chosen for the often obvious contradictions in the participants' perceived effects.

\section{4. $\quad$ Findings}

\subsection{Effects of exposure to traumatic narratives}

The interpreter-perceived effects of exposure to the traumatic narratives of migrant children and the ways in which they had affected the interpreter's well-being are described in this section. They are broadly categorized as: (1) effects during the interpreted event (short-term) and (2) effects following the interpreted event (long-term). The degrees and types of effect of exposure to traumatic content are divided into subsections and supported by specific examples from the participants.

\subsubsection{During the interpreted event}

Many participants reported feelings of sadness and anger during the interpreting assignment. One participant experienced sadness during the event due to "the lack of empathy from the officer" or "hearing that they [the child] were mistreated when they were in immigration detention or the safe house". Another participant, upon seeing the attorney cry, also began crying while interpreting the account, despite their effort to maintain a professional attitude and focus on the task at hand. Other participants, although they often felt prepared, were affected in the moment, one of them stating:

I have read a lot of psychology books, before going into this stuff so I have certain knowledge, but once you hear it first-hand, especially from a small voice, like a child, you kind of feel the tension ... You are affected in the moment. Your job is to interpret and to try to focus 'cause they're usually crying; so, you're trying to focus on what they're saying: Do I know this word? Where are they from?

Another participant was affected during an event in which their client was being questioned in a language he did not fully understand:

I remember just being affected in my interpretation because the young man didn't understand, and the reason he didn't understand was because ... he was ... I believe another Guatemalan child; his first tongue was not Spanish; it was one of the indigenous languages. And so, that also affected my performance... Knowing that this child wasn't understanding and thus not responding in the complete manner ... it affected me more on a level of like ... this person should have an interpreter of his native language rather than Spanish, because he would likely, I would hope, understand better and there wouldn't be any potential confusion or, even worse, questions answered in the wrong way because he didn't understand Spanish.

Many participants reported feeling affected due to past personal experiences. One participant felt it "hitting close to home" because they were also Central American. And although they were able to detach in the moment, they felt upset at the degree of "abuse toward children" and feeling angry and "disgusted" afterwards. 
Sultanić, I. (2021). Interpreting traumatic narratives of unaccompanied child migrants in the United States: Effects, challenges and strategies. Linguistica Antverpiensia, New Series: Themes in Translation Studies, 20, 227-247.

One participant spoke of their background:

This is really personal, but my mother is a concentration camp survivor and as a child, she had to flee and was caught. And so, for me, I think that this issue of what's going on right now is excruciating for me in a really deeply personal way.

Other participants also reported getting "choked up" but managing to maintain their composure and focus on the task at hand.

\subsubsection{Following the interpreted event}

For many participants, the after-effects seemed minimal, lingering only for a day. For others, though, the interpreted event had a negative impact on their personal lives. One participant felt that they are sometimes triggered by the stories in the media, stating:

When I see headlines or news relating to these types of stories I also feel like a sense of helplessness, and I still get like angry.

Others reported crying afterwards as an emotional release, with one participant sharing: "Sometimes I cry afterward ... it doesn't affect my sleeping, my eating, my daily life."

Several participants felt that it had a negative impact on their physical and mental health. For one participant, the effects began manifesting in their sleep:

I have nightmares about one particular case. There was a young child I interpreted for who was not well as a result of passing through multiple immigration detention centers, and that child has a physical likeness a lot, looks a lot like my stepson ... And I do have nightmares, very rarely, and they're not very vivid, very shocking nightmares, but his hands, the child's hands show up in my nightmare and it's very difficult for me to differentiate between that child's hands and my stepson's hands because they're very similar in appearance ... So, I would say that affected me a lot, and it still, every once in a while, creeps up on me unexpectedly out of the blue ...

Another participant noticed the cumulative effects of prolonged exposure on their mental health. One case also affected their physical health, when they had to stand close to a client who had strep throat (i.e., streptococcal pharyngitis), who then passed it on to them. For other participants, the effects manifest themselves in personal relationships, where they feel "triggered by stuff" or feel "a little less trusting" or "a little more aware of what people are capable of".

\subsubsection{Positive effect}

Some participants felt that they were not affected emotionally, but that, as one participant related, they felt "more sympathetic". Similarly, others reported an increased desire to volunteer and perfect their interpreting skills so as to help the migrant children. They noticed that these stories made them more thoughtful, more "aware of other people's situations". They were "eye-opening", a "reality check", and made them feel "more human". 
Sultanić, I. (2021). Interpreting traumatic narratives of unaccompanied child migrants in the United States: Effects, challenges and strategies. Linguistica Antverpiensia, New Series: Themes in Translation Studies, 20, 227-247.

One interpreter went so far as to say: "I guess the way that it has affected [sic] is that it has really led me to increase my resolve to continue working in that environment." To do "more research", to "read" more, adding that "it doesn't affect me emotionally ... my years of experience allow me to be empathic without being involved". Another participant stated that it "is healing to help these people, to give these kids a voice".

\subsubsection{Reduced impact due to experience}

Several participants shared that they "probably get less shaken than the younger set" due to a wide range of experiences as well as their age. Some felt that because of their dual role, serving as both an advocate and an interpreter, they were able to maintain their professional boundary when interpreting, although the lines were often blurred beyond the interpreting task. They recognized that the impact of the traumatic content would be different if they were only assuming the role of an interpreter who was hearing the account firsthand and for the first time in a courtroom setting. In addition, they recognized that when the setting is "more formal there is kind of a very strict division of roles".

Other participants cited professionalism and the fact that interpreters are not allowed to show emotion during an interpreted event as reasons for not feeling affected. One interpreter felt that the effect of VT had not manifested itself, while acknowledging:

It's a form of vicarious trauma that an interpreter goes through. But, at the same time, the challenge is that you cannot show emotion when you are interpreting so you have to kind of keep your cool while you're interpreting, and just continue to be that conduit and ... not show any emotion ...

Similarly, some felt strongly about staying within their role boundaries, with one interpreter maintaining:

As a professional interpreter, you have to know how to dissipate these feelings that you feel upon retelling someone else's story, you just have to find a way to dissipate this vicarious trauma.

Yet, for others, although they were affected in the moment, it was helpful not to dwell on the content of the story and simply to move on to the next case, or not to take the story and the emotions home with them.

\subsection{Challenges of interpreting children's narratives}

The participants were asked to report on those aspects of interpreting the traumatic narratives of child migrants they perceived as the most challenging or difficult. The interpreters' responses have broadly been categorized into (1) linguistic challenges, (2) emotional challenges and (3) role boundaries.

\subsubsection{Linguistic}

The participants' perceived challenges and difficulties with regard to language have been categorized as follows: (a) the language level of the child and their ability to communicate 
Sultanić, I. (2021). Interpreting traumatic narratives of unaccompanied child migrants in the United States: Effects, challenges and strategies. Linguistica Antverpiensia, New Series: Themes in Translation Studies, 20, 227-247.

what has happened to them using the right words; (b) the age of the child; and (c) the interpreter's knowledge of the right terminology and consequently their ability to "retell" the story accurately.

One participant reported the following challenges:

The most difficult was just understanding them ... I felt that most times I could only understand about $80 \%$ of what they were saying. And, of course, they don't have the intellectual maturity to know kind of how to slow down, or they don't even have access to a higher register of language.

They stated further that one of their clients "wasn't even a native Spanish speaker". The client spoke Acateco and "had learned Spanish through her migration and ultimate settling in a home with all Spanish-speakers". Similarly, another participant reported the difficulty of interpreting for a child who was not fully understanding the questions or how to respond since their first language was an indigenous language, yet the language of interpretation was Spanish.

One participant shared:

I have been in situations where I don't know if I am dealing with a non-responsive child, that because of the situation or because they just don't have the words. A lot of times they don't have the vocabulary, the fact that they are functionally illiterate. It, it's a barrier ... I may be dealing with a 15-year-old who went to just third grade ... Especially if you think about those families, those children whose language is Indigenous, it's not Spanish, and they're forced to speak Spanish.

What made it difficult for one participant was that "children will rapid fire, give you so much detail about what had happened ... what they felt, even the temperature, things like that", while others felt the opposite, as exemplified below:

I think sometimes children don't necessarily know how to explain what happened to them. Or they are ... either embarrassed or unsure of how to communicate it or they don't want to get in[to] trouble, or they're not even a hundred percent sure what it is that happened to them. So, asking the right questions, and making sure that I'm understanding what they're saying correctly and not misinterpreting or adding to the story or filling in blanks is really difficult.

The challenge, according to some participants, was also the interpreter's lack of familiarity with the specific terminology used in immigration settings. One participant felt that one of the "difficult things ... is the verbiage", adding that they "did not know there was a set glossary of terms specifically dealing with URM cases in court", and that they "stumbled upon that later on".

For others, the challenge was using the correct terminology to describe the living conditions:

Probably interpreting the living situations or the conditions in different countries and ... translating that in[to] English. So, for example, some of the challenging pieces that I've had in the past is how to explain, you know, some of these children comes [sic] from where they live 
Sultanić, I. (2021). Interpreting traumatic narratives of unaccompanied child migrants in the United States: Effects, challenges and strategies. Linguistica Antverpiensia, New Series: Themes in Translation Studies, 20, 227-247.

it's not technically a village, sometimes it's not a city, it's very remote, and kind of explaining that part of it ... and the lifestyle, how they live ... that piece is the hardest part.

There were also a few participants who felt that "because the interpreter comes from the same or similar background as the child", they were able to "communicate with them when it comes to different terminology or dialect" and they were "able to connect with them" without further elucidating whether any actions they took in those settings challenged their role boundary, or if this was to illustrate that they faced no challenges.

\subsubsection{Emotional}

Regarding emotional challenges, many participants reported issues arising from the child's emotions, the interpreter's perception of the child's emotions, the interpreter's own emotions and the emotional burden placed on them.

One participant observed:

They don't understand the world like an adult does, so the way in which they express the emotions towards the situations in which they find themselves, whether it be anger, or whether it be just complete vulnerability, and just sadness, the intensity with which they feel those emotions, is just, I feel like it's magnified. And being able to convey those emotions accurately and completely is very difficult as an interpreter.

Another participant said: "I am especially moved by when they look fearful. ... which is often the case, they are just scared, they're confused" adding that at times "they don't even know the extent of what they've been through or how important it is what they've been through".

One interpreter described the difficulty of interpreting for a child who experienced physical or sexual abuse "by someone they had met, or a stranger at the border" and the child being "conflicted" and "shy" about answering those questions posed by the officer - another stranger to them - but also lacking "an understanding of certain terminology" to answer such questions.

In other instances, the interpreters observed that the children understood why they had to flee, and despite having a complete, albeit interpreter-perceived understanding of why they had to flee in the first place, that was "the hardest trauma" that they identified. Another participant observed that "these experiences are traumatic" and found that having a "serious face" and distancing themselves from "what they're [the children] saying" and not showing emotion as "the most difficult part".

For one participant it was "seeing a child relive these traumatic experiences"; they stated:

Because you know they are children, and these are things that they shouldn't have gone through in the first place, and just having to interpret all of this in a professional way without letting your emotions, or your opinion, what you're thinking, show ... just remain[ing] professional in the face of a child who's, you know, reliving something that is truly traumatic and you have to picture all of this, and interpret it, that's sometimes really tough. 
Sultanić, I. (2021). Interpreting traumatic narratives of unaccompanied child migrants in the United States: Effects, challenges and strategies. Linguistica Antverpiensia, New Series: Themes in Translation Studies, 20, 227-247.

These experiences also present an emotional burden for the interpreter, who already feels a great deal of responsibility in telling the child's story completely and accurately yet must refrain from consoling a scared and/or a traumatized child. One participant reported:

I feel like it's really important for me not to have my own feelings and my own emotions, and just to try really hard to hold the child's emotions and to pass those on; and when I hear something excruciating and the child is crying, and shaking, and scared, it's very difficult not to reach out and hold them, or not cry ... When they're crying and I'm saying their words, that's hard ... I mean ... it is supporting them to say their words, but ... you cannot reach over and put your hand at least on their shoulder ... or take their hand ... And nobody's doing it and they're alone, shaking ....

For one interpreter it was "listening to their background story", while for another it was the emotion that the adult extrapolates from background knowledge and the child's journey and not so much what the child actually says or the emotion that they attach to it. For others, the challenge is trying not to get emotional upon hearing the stories and visualizing what happened, including not relating it to their own life.

For several interpreters, the challenge and the difficulty were in the "how" to emote and convey the emotion, whether it be by choosing to "modulate" their voice to "keep the tone very warm, especially when you're talking to someone who's talking about a traumatic event, and that you're trying to have them open up", or to "help them feel safe". This is the case especially, as two participants reported, when the attorney or the officers demonstrate a lack of empathy, or when the children have been mistreated by the immigration system.

\subsubsection{Role boundary}

\subsubsection{Staying within professional boundaries}

For some participants, the greatest challenge was staying within the professional boundaries and adhering to their code of ethics. One interpreter cites being the conduit as "one of the most challenging or difficult aspects" and having to "retell that [sic] to the judge or referee".

Another interpreter was very candid about the difficulty of walking the fine line between the professional boundary and personal involvement:

I would say it's hard to, just to ask the questions ... just to be there as a bystander ... I think it's hard ... I know that the attorneys are helping but if the child doesn't want to answer some questions ... And you are there, and you are trying to help ... you're not supposed to try to help, but you are, you want to make a good case for this kid ... If this kid doesn't make a good case in court, he's going to go right back [to] where he came from, and he's going to get deported. And you don't want that, and I guess the attorneys don't want that.

For one participant the three challenges (linguistic, emotional and role boundary) were all very much intertwined:

I always say that, working with kids, working in asylum cases, is when legal meets the mental health field. They come together. Because they are giving a declaration, you have to say 
Sultanić, I. (2021). Interpreting traumatic narratives of unaccompanied child migrants in the United States: Effects, challenges and strategies. Linguistica Antverpiensia, New Series: Themes in Translation Studies, 20, 227-247.

everything as you hear it, you have to convey it as close as possible ... You convey the best you can, as close as possible, but we also understand that this is a declaration, but at the same time it's like you're touching very difficult emotions and events so there also has to be that sensitivity ... Sometimes the officers have it, sometimes they don't. The interpreter needs to be aware of that because this can make or break a case. Be professional, but there needs to be also warmth ... you can transmit that without stepping out of your professional role.

\subsection{Coping strategies}

The participants were asked which coping strategies and mechanisms they employ while interpreting to help maintain their composure and remain within the boundaries of their professional role. The following are examples of both the general and the specific coping mechanisms reported on by the participants. They are broadly categorized into (1) coping strategies during the interpreted event; (2) coping strategies following the interpreted event; and (3) the absence of coping strategies.

\subsubsection{Coping strategies during the interpreted event}

Almost all the participants reported the following coping strategies and mechanisms as those they relied on during an interaction:

- focusing on the task at hand;

- holding on to a "stress ball" or "something soft" as a way of grounding oneself;

- going into the assignment focusing on their role as the conduit and reminding themselves that the message is not theirs, it's the speaker's;

- taking notes to have "something to hold on to" and being in "hypersensitivity mode" as the first one to hear the message in either language;

- breathing during the assignment;

- reminding oneself that one is there to help the children and hoping for a good outcome;

- shutting oneself off emotionally while interpreting as a form of self-preservation by assuming the role of an "actor" during the interaction.

This last point is exemplified by one participant's response:

When I was in [sic] my university ... they always told us that when we're interpreting, we stop being ourselves. We become kind of like an actor or an actress and we impersonate the doctor and the patient, we just kind of like alienate ourselves from the situation ... I think that I have built this persona when I'm interpreting ... I've shut myself [off] from the situation when interpreting. Sometimes it's really hard when you're about to interpret for a migrant child, you never know the story, you never know what you're going to find until you walk in.

\subsubsection{Coping strategies following the interpreted event}

The list below itemizes the coping strategies reported by most participants as those they principally relied on after an interpreting assignment: 
Sultanić, I. (2021). Interpreting traumatic narratives of unaccompanied child migrants in the United States: Effects, challenges and strategies. Linguistica Antverpiensia, New Series: Themes in Translation Studies, 20, 227-247.

- talking to someone (another interpreter, colleague, supervisor, community organizer or others in the same line of work who understand the work they do);

- applying coping strategies learned and used for coping with personal trauma such as:

○ spending time alone

- receiving physical contact and affection from loved ones

- guided meditation

o sleeping;

- doing physical exercise;

- participating in comedy;

- reading;

- undergoing a psychological evaluation for other stressors in one's personal life, which also serves as an evaluation of one's emotional state due to exposure to VT during interpreting;

- turning to one's faith and prayer;

- going to therapy routinely;

- taking a shower and visualizing the event "wash away";

- going on long walks, alone or with a dog to calm oneself;

- rewinding the story in one's head, reflecting on the events, processing, and then moving on;

- finding refuge at home, with family.

Most participants referred to the importance of engaging in any form of self-care to get one's mind off things.

\subsubsection{Perceived lack or absence of coping strategies}

A small number of participants did not feel that they could classify their routines as specific strategies, although it is apparent from their answers that they did in fact employ coping strategies. In this regard, one participant said:

I don't think I have any specific techniques, no. I just go, I interpret, and then I just try to think positive ... I guess I just try to do things to get distracted ... I really like music and reading and those are the two things that I do ...

One participant felt that a lack of strategy might be the "problem", saying:

None whatsoever, and I feel that was exactly the problem ... I was not trained to have a strategy or, or a method, or anything to, to cope with it, and it's the, by the end of a certain period, it's just accumulated load.

To this they added that they speak to other interpreters or colleagues to "unload".

Another participant, even though they felt that they did not have a specific strategy, shared that they had others around them who were in the same line of work and who were "processing these stories" and "have a shared mission", which made them feel supported. 
Sultanić, I. (2021). Interpreting traumatic narratives of unaccompanied child migrants in the United States: Effects, challenges and strategies. Linguistica Antverpiensia, New Series: Themes in Translation Studies, 20, 227-247.

\section{Discussion}

It is evident from the findings of this study that all the participants were affected by their exposure to the traumatic narratives of unaccompanied migrant children, whether during the interpreted event or after it took place. The degree of formality of the interpreted event - in addition to the interpreter's training and education, personal trauma and experience, age and years in the profession - seems collectively to have had an impact on their overall perception of the effects of exposure. Furthermore, some participants even reported that interpreting in these highly emotional settings had a positive effect on them in that, although the experiences were heart-breaking, the contribution they were making with their language assistance gave them the resolve to continue with this kind of work. This positive effect, as Splevins et al. (2010) have argued, could be classified as vicarious post-traumatic growth (VPTG). Although these positive changes occur in individuals "as a result of directly experiencing trauma", the effect that interpreting in such settings had on some participants suggests that "it might be expected that those working with trauma survivors will also experience vicarious posttraumatic growth" (p. 1706).

The challenges described by the participants were many, including linguistic, cognitive and emotional challenges. Linguistic challenges - such as the child's language level, age and conceptualization of the world, and even the fact that, in some instances, the children were being interviewed in their second language - all seem common in these settings. Much like the interpreters who worked in the United Nations International Criminal Tribunal for Rwanda who repeatedly "listened, visualised, analysed, understood and re-expressed what they heard" (Ndongo-Keller, 2008, p. 337), the interpreters working with unaccompanied migrant children had to relay the information in the first person. Often, they themselves had lived through a similar traumatic experience, which can lead to internalization, VT and even re-traumatization.

Emotional challenges and setting role boundaries are the greatest indicators of the degree of both cognitive and emotional effort required during interpreting. The surprising finding with respect to short- or long-term effects, emotional challenges and coping mechanisms used during an interpreted event - especially when role boundaries were tested - is that, despite the perceived difficulties, none of the participants reported an inability to continue with an assignment or a need to withdraw. This could be due to intentional or spontaneous application of coping strategies during the event, which were effective in enabling them to continue. In fact, the way many participants approached the work, and the coping mechanisms employed, whether consciously or subconsciously, is in line with the coping strategies identified by Lai and Costello (2020, p. 77):

1. personal - including spiritual care, healthy lifestyle, self-care, hobbies;

2. cognitive - including positive thinking, reframing, problem-solving, distraction;

3. emotional - including medication, relaxation techniques;

4. physical - including yoga, exercise, muscle relaxation;

5. interpersonal - including informal debriefing, peer support. 
Sultanić, I. (2021). Interpreting traumatic narratives of unaccompanied child migrants in the United States: Effects, challenges and strategies. Linguistica Antverpiensia, New Series: Themes in Translation Studies, 20, 227-247.

These coping strategies can be classified and conceptualized further under the dimensions of emotional labor described by Guy et al. (2008, pp. 5-6):

Compassion fatigue was experienced by most participants. Professional face, a form of emotional distancing, was employed by some participants to help them stay within the role boundaries, focusing on their role as conduit and reminding themselves that the message is not theirs, it is the speaker's. Some were successful in establishing rapport, while others took on an actor persona, which is in line with stage left, but also emotional suppression or shutting themselves off emotionally. Emotional armor and emotional teflon were both used by some to protect themselves from their "own emotional response" when they felt emotions welling up. Those who exhibited empathy entered the dimension of emotional engagement. Others were good at not showing any emotion by wearing an emotional mask.

All the participants employed some form of a coping mechanism or strategy, both during (as described above) and after the interpreted event. The coping strategies that followed an interpreted event are as varied as the responses to the traumatic narratives themselves. Many of the strategies align with self-care, while others involved a degree of peer and professional support. Even the participants who could not identify a specific strategy had support networks, spoke to colleagues and coped to the best of their ability, recognizing, in some instances, that strategies were never taught in any of their interpreter training sessions.

The common denominator among the participants, as indicated by the response data, is the inability to unload the accumulated emotional burden from an interpreted event safely and with adequate professional support. This indicates a lack of support for interpreters' mental health, which has also been identified by Amato and Mack (2015) in their study on briefing, debriefing and support for interpreters working with minors in legal settings. Furthermore, it speaks to the dire need for including VT, its signs and symptomatology, in specialized interpreter training and educational models, and for designing frameworks that are specific to working with children and other vulnerable populations.

Historically, interpreter self-care and coping techniques have largely been an afterthought, although, recently, as more evidence-based research has become available, this important topic is becoming more recognized and educational models are being created and proposed (see Crezee et al., 2015, for more). Since many interpreters already use coping strategies that align with the dimensions of emotional labor identified by Guy et al. (2008), these dimensions could then be reimagined as an interpreter assessment tool and incorporated into PSI curricula.

\section{Conclusion}

The effects of exposure to traumatic narratives told by children and the challenges of interpreting for this vulnerable group are undeniable, whether short-lived (during the assignment) or lingering well beyond the interpreted event. The findings of this study point to the need for interpreter-specific counseling and both peer and professional support. Moreover, they emphasize the need for training and education on trauma-informed interpreting involving both adults and children. Although stress, VT, compassion fatigue and 
Sultanić, I. (2021). Interpreting traumatic narratives of unaccompanied child migrants in the United States: Effects, challenges and strategies. Linguistica Antverpiensia, New Series: Themes in Translation Studies, 20, 227-247.

burnout are all considered occupational hazards of public service interpreting, it should not be left to the interpreter to identify and acquire the necessary skills and professional support they require to cope. VT or vicarious traumatization must be dealt with during training so that the interpreters have a better understanding of the signs, symptoms and effects. This will allow them to develop preventive measures and proper coping strategies to mitigate any lasting effects, including potential triggers.

This study is, of course, not without its limitations: it is based on a small sample of interpreters and on interpreter-perceived effects of exposure to traumatic narratives told by children and the challenges of interpreting in these contexts. It is, however, in line with the findings of studies conducted by Lor (2012), Lai et al. (2015), Lai and Costello (2020), Crezee et al. (2011) and Barreto Abrams (2020). Nevertheless, further research is required on the effects of exposure to traumatic narratives on interpreters working in trauma-informed settings involving refugee children in the United States. 
Sultanić, I. (2021). Interpreting traumatic narratives of unaccompanied child migrants in the United States: Effects, challenges and strategies. Linguistica Antverpiensia, New Series: Themes in Translation Studies, 20, 227-247.

\section{References}

Amato, A., \& Mack, G. (2017). Interpreters working with children in Italy: Profile, role, and expectations. InTRAlinea, 19. https://www.intralinea.org/index.php/archive/article/2263

Amato, A., \& Mack, G. (2015). Briefing, debriefing and support. In K. Balogh \& H. Salaets (Eds.),

Children and justice: Overcoming language barriers (pp. 247-280). Intersentia.

American Immigration Council. (2020). Asylum in the United States. https://www.american immigrationcouncil.org/research/asylum-united-states

Balogh, K., \& Salaets, H. (Eds.). (2015). Children and justice: Overcoming language barriers. Intersentia. https://doi.org/10.1017/9781780685144

Barreto Abrams, J. O. (2020). Vicarious trauma as a psychosocial occupational hazard in the field of sign language interpreting. (Publication No. 28029372) [Doctoral Dissertation, Gallaudet University]. ProQuest Dissertations and Theses Global.

Birck, A. (2001). Secondary traumatization and burnout in professionals working with torture survivors. Traumatology, 7(2), 85-90. https://doi.org/10.1177/153476560100700203

Björn, G. J. (2005). Ethics and interpreting in psychotherapy with refugee children and families. Nordic Journal of Psychiatry, 59(6), 516-521. https://doi.org/10.1080/08039480500360740

Bontempo, K., \& Malcolm, K. (2012). An ounce of prevention is worth a pound of cure: Educating interpreters about the risk of vicarious trauma in healthcare settings. In L. Swabey \& K. Malcolm (Eds.), In our hands: Educating healthcare interpreters (pp. 105-130). Gallaudet University Press.

Böser, U., \& LaRooy, D. (2018). Interpreter-mediated investigative interviews with minors: Setting the ground rules. Translation and Interpreting Studies, 13(2), 208-229. https:// doi.org/10.1075/tis.00012.bos

Boyle, D. A. (2015). Compassion fatigue: The cost of caring. Nursing, 45(7), 48-51. https://doi.org/ 10.1097/01.NURSE.0000461857.48809.a1

California Healthcare Interpreting Association. (2002). California standards for healthcare interpreters: Ethical principles, protocols, and guidance on roles \& intervention. https://www.chiaonline.org/resources/Pictures/CHIA standards manual \%20March\%2020 17.pdf

Crezee, I., Atkinson, D., Pask, R., Au, P., \& Wong, S. (2015). Teaching interpreters about self-care. International Journal of Interpreter Education, 7(1), 74-83.

Crezee, I., Jülich, S., \& Hayward, M. (2011). Issues for interpreters and professionals working in refugee settings. Journal of Applied Linguistics and Professional Practice, 8(3), 253-273. https://doi.org/10.1558/japl.v8i3.253

Figley, C. R. (Ed.). (1995). Compassion fatigue: Coping with secondary traumatic stress disorder in those who treat the traumatized. Brunner/Mazel.

Guy, M. E., Newman, M. A., \& Mastracci, S. H. (2008). Emotional labor: Putting the service in public service. Routledge. https://doi.org/10.4324/9781315704852

International Medical Interpreters Association. (2019). IMIA code of ethics. https://www.imia web.org/uploads/pages/376.pdf

Killman, J. (2020). Interpreting for asylum seekers and their attorneys: The challenge of agency. Perspectives: Studies in Translation Theory and Practice, 28(1), 73-89. https:// doi.org/10.1080/0907676X.2019.1615518

Keselman, O., Cederborg, A.-C., Lamb, M. E., \& Dahlström, Ö. (2008). Mediated communication with minors in asylum-seeking hearings. Journal of Refugee Studies, 21(1), 103-116. https://doi.org/10.1093/irs/fem051

Keselman, O., Cederborg, A.-C., Lamb, M. E., \& Dahlström, Ö. (2010a). Asylum-seeking minors in interpreter-mediated interviews: What do they say and what happens to their responses? 
Sultanić, I. (2021). Interpreting traumatic narratives of unaccompanied child migrants in the United States: Effects, challenges and strategies. Linguistica Antverpiensia, New Series: Themes in Translation Studies, 20, 227-247.

Child and Family Social Work, 15(3), 325-334. https://doi.org/10.1111/i.13652206.2010.00681.x

Keselman, O., Cederborg, A.-C., \& Linell, P. (2010b). "That is not necessary for you to know!": Negotiation of participation status of unaccompanied children in interpreter-mediated asylum hearings. Interpreting, 12(1), 83-104. https://doi.org/10.1075/intp.12.1.04kes

Knodel, R. K. (2018). Coping with vicarious trauma in mental health interpreting. Journal of Interpretation, 26(1), 1-23.

Kurz, I. (1997). Interpreters: Stress and situation dependent control of anxiety. In K. Klaudy \& J. Kohn (Eds.), Transferre necesse Est: Proceedings of the 2nd international conference on current trends in studies of translation and interpreting (pp. 201-206). Scholastica.

Kurz, I. (2002). Physiological stress responses during media and conference interpreting. In G. Garzone \& M. Viezzi (Eds.), Interpreting in the 21st century: Challenges and opportunities (pp. 195202). John Benjamins. https://doi.org/10.1075/btl.43.19kur

Lai, M., Heydon, G., \& Mulayim, S. (2015). Vicarious trauma among interpreters. International Journal of Interpreter Education, 7(1), 3-22.

Lai, M., \& Costello, S. (2020). Professional interpreters and vicarious trauma: An Australian perspective. Qualitative Health Research, 31(1), 70-85. https://doi.org/10.1177/1049 $\underline{732320951962}$

Lor, M. (2012). Effects of client trauma on interpreters: An exploratory study of vicarious trauma [Master's thesis, St. Catherine University]. SOPHIA. https://sophia.stkate.edu/ cgi/viewcontent.cgi?article $=1053 \&$ context $=$ msw papers

Loutan, L., Farinelli, T., \& Pampallona, S. (1999). Medical interpreters have feelings too. Sozial- und Präventivmedizin, 44, 280-282. https://doi.org/10.1007/BF01358977

Miller, M. (2005). The role of interpreters in psychotherapy with refugees: An exploratory study. American Journal of Orthopsychiatry, 75(1), 27-39. https://doi.org/10.1037/0002$\underline{9432.75 .1 .27}$

Musacchio, M. (2013). El impacto psicológico de los intérpretes en el ámbito de la salud mental: el caso del síndrome de Ulises. [Master's thesis, Universidad de Alcalá]. https://ebuah.uah.es/xmlui/bitstream/handle/10017/23778/TFM \%20AnaMorales El\%20i mpacto\%20psicol\%C3\%B3gico\%20en\%20el\%20int\%C3\%A9rprete.pdf\%20\%28p\%29.pdf?seq uence $=1$ \&isAllowed $=y$

National Association of Judiciary Interpreters and Translators. (n.d.). Code of ethics and professional responsibilities. https://najit.org/wp-content/uploads/2016/09/NAJITCodeofEthicsFINAL.pdf

National Council of Interpreting in Health Care. (2005). National standards of practice for interpreters in healthcare. $\quad$ https://www.ncihc.org/assets/z2021lmages/NCIHC\%20Na tional\%20Standards\%20of\%20Practice.pdf

Ndongo-Keller, J. (2015). Vicarious trauma and stress management. In H. Mikkelson \& R. Jourdenais (Eds.), The Routledge handbook of interpreting (pp. 337-351). Routledge. https://doi.org/10.4324/9781315745381

Nilsen, A. B. (2013). Exploring interpreting for young children. Translation and Interpreting 5(2), 1429. http://www.trans-int.org/index.php/transint/article/view/224

Nilsen, A. B. (2015). Interpreted communication with children in public-sector services. Translation and Interpreting, 7(3), 121-131. http://www.trans-int.org/index.php/ transint/article/view/376

Palm, K. M., Polusny, M. A., \& Follette, V. M. (2004). Vicarious traumatization: Potential hazards and interventions for disaster and trauma workers. Prehospital and Disaster Medicine, 19(1), 7378. https://doi.org/10.1017/S1049023X00001503

Pearlman, L. A., \& Saakvitne, K. W. (1995). Treating therapists with vicarious traumatization and secondary traumatic stress disorders. In C. R. Figley (Ed.), Compassion fatigue: Coping with 
Sultanić, I. (2021). Interpreting traumatic narratives of unaccompanied child migrants in the United States: Effects, challenges and strategies. Linguistica Antverpiensia, New Series: Themes in Translation Studies, 20, 227-247.

secondary traumatic stress disorder in those who treat the traumatized (pp. 150-177). Brunner/Mazel.

Pöllabauer, S. (2004). Interpreting in asylum hearings: Issues of role, responsibility and power. Interpreting, 6(2), 143-180. https://doi.org/10.1075/intp.6.2.03pol

Pöllabauer, S. (2015). Interpreting in asylum proceedings. In Mikkelson H. \& Jourdenais R. (Eds.), The Routledge handbook of interpreting (pp. 202-216). Routledge. https://doi. org/10.4324/9781315745381

Powell, M. B., Manger, B., Dion, J., \& Sharman, S. J. (2017). Professionals' perspectives about the challenges of using interpreters in child sexual abuse interviews. Psychiatry, Psychology and Law, 24(1), 90-101. https://doi.org/10.1080/13218719.2016.1197815

Sexton, L. (1999). Vicarious traumatisation of counsellors and effects on their workplaces. British Journal of Guidance \& Counselling, 27(3), 393-403. https://doi.org/10.1080/ $\underline{03069889908256279}$

Splevins, K. A, Cohen, K., Joseph, S., Murray, C., \& Bowley, J. (2010). Vicarious posttraumatic growth among interpreters. Qualitative Health Research, 20(12), 1705-1716. https:// doi.org/10.1177/1049732310377457

UNICEF (2018, August). Child alert: Uprooted in Central America and Mexico. https://www. unicef.org/lac/sites/unicef.org.lac/files/2018-08/20180814 UNICEF-ChildAlert-2018CentralAmericaMexico.pdf

U.S. Customs and Border Protection. (n.d). Southwest border migration. Retrieved December 1, 2020, from https://www.cbp.gov/newsroom/stats/sw-border-migration

Valero Garcés, C. (2015). The impact of emotional and psychological factors on public service interpreters: Preliminary studies. Translation and Interpreting, 7(3), 90-102. https://doi. org/10.12807/ti.107203.2015.a07 